\title{
Construct and Dimensions of Authenticity in Strategic Communication Research
}

Juan-Carlos Molleda, Ph.D.*

Recibido: 25 de octubre de 2009

Aceptado: 23 de noviembre de 2009

\begin{abstract}
With the purpose of going around the dilemma between evilness or apology of media, this article proposes the Popper analytics -conceptually elaborated by Michel Foucault, and more specifically the concept of Power Relations - as a perspective which allows noticing some of the characteristics of power analysis which results from the virtual interaction. The arena of this reflection will be the concept of Control Corporations, as an own configuration of contemporaneous companies
\end{abstract}

Key words: Power, virtuality, control, social networks, communication media

* University of Florida 


\title{
El Constructo y las dimensiones de autenticidad en la investigación de comunicación estratégica
}

\begin{abstract}
RESUMEN
Con el fin de rodear un poco la disyuntiva entre demonización o apología de los medios, el presente escrito propone la analítica del poder -elaborada conceptualmente por Michel Foucault, y concretamente la noción de Relaciones de poder- como perspectiva que permita asomarse a algunas de las características que reviste el ejercicio del poder que tiene lugar a partir de la interacción virtual. El escenario de esta reflexión será, a su vez, la noción de Sociedades de Control, como configuración propia de las sociedades contemporáneas.
\end{abstract}

Palabras clave: Poder, virtualidad, control, redes sociales, medios de comunicación. 


\section{INTRODUCTION}

This article introduces the construct authenticity and its various theoretical dimensions. The emphasis is on strategic communication (i.e., advertising, marketing, and public relations) in which the expertise and research interests of the author reside. Furthermore, authenticity is central to the study and practice of strategic communication and its specialized fields because organizations are being pressured by societies demanding greater transparency, clarity, and responsibility from organizations and their spokespeople.

This article draws definitions and contributions from scholars of a variety of disciplines devoted to the study of communication. This is relevant because we are in an era in which interdisciplinary knowledge is needed to understand the greater complexity of our society, cultures, and segmented audiences, vis-à-vis communication studies and the ever-changing communication industry.

The following series of definitions of authenticity confirms the versatility of the keyword to explain an array of communication phenomena, from intra- and interpersonal communication to corporate and mass mediated communication. Since the 1970s, there has been a critical amount and quality research on authenticity. This research could inform and guide current and future studies in which the truthfulness and genuine character of who we are as encoders and interpreters of meaning, the communication products and media we produce, and the audiences or publics we engage are at the core of the construct in question.

According to the Oxford English Dictionary (1989), being authentic is being reliable, trustworthy, original, firsthand, and prototypical as opposed to copied. Authenticity is the quality of being true in substance, and such quality is essential for antiques and art. The Merriam-Webster Dictionary and Thesaurus online (Authentic, 2009) offers synonyms of being authentic, such as real, actual, genuine, and bona fide (i.e., being actually and exactly what is claimed). These elements are similar to the variables that define source credibility in mass communication literature. The dictionary also presents the following definitions: "[W]orthy of acceptance or belief as conforming to or based on fact ...; conforming to an original so as to reproduce essential features ...; made or done the same way as an original ...; not false or imitation ...; and true to one's own personality, spirit, or character" (n.p.).

The above definitions could be used to describe individuals, objects, communication products and events, and organizations of all kinds. For instance, organizations progressively build their identities or corporate personalities by highlighting and putting certain "authentic" features out to the scrutiny of their audiences, consumers, stakeholders, or publics who, at the same time, make selective interpretations and consequently define the reputations of these organizations. The consistency of what organizations do and say may result in an image or reputation close to the carefully built corporate identity with the use of strategic communication.

The issue of perceived authenticity can determine the organization-public dynamic. From this view, Trilling (1972) thought authenticity of an object as the function of perceived genuineness and positive valuation. In the same decade, Theodor W. Adorno (1973), who is often quoted by communication scholars, especially supporters of a critical perspective, wrote the book The jargon of authenticity. For instance, Hardt (1993) explained that Adorno "sees the danger of this jargon on its reception by individuals who continue to believe in their own importance and the shared experience of an illusory reality through the power of communication" (p. 52). Building the authenticity of an object, idea, or organization 
using communication without being authentic in reality and substance will not be possible to sustain these corporate identities and the relationships they help to develop over time.

More recently, Frosh (2001) defined authenticity from a mass cultural production approach as "'truth-to-oneself,' a project of ontological fidelity that takes particular discursive forms: in the aesthetic realm, it stresses the creativity of the individual artistic personality (the artist is therefore 'true to' his or her own individual 'genius'), and the formal and expressive uniqueness of the artwork (the artwork is 'true to' its own internal formal necessity, and often transgresses accepted formats)" (p. 542). Frosh analyzed stock photography as a mass cultural production to argue that cultural inauthenticity is characterized by salient features, such as the dominance of a generic formula, product uniformity, and the supremacy of commercial imperatives. These aspects are being challenged by audiences or consumers skeptical of a myriad of repetitive and inconsequential organizational promises.

Fine's (2003) definition of authenticity reads: "[S|incere, innocent, original, genuine, and unaffected....linked to moral authority of the creator and simultaneously to the fact that the object was made by hand, not mechanically produced" (p. 155). From a strategic communication approach, Beverland (2005) defined authenticity as "a story that balances industrial (production, distribution and marketing) and rhetorical attributes to project sincerity through the avowal of commitments to traditions (including production methods, product styling, firm values, and/or location), passion for craft and production excellence, and the public disavowal of the role of modern industrial attributes and commercial motivations" (p. 1008). Here again the public seems to be empowered to weed out repetitive and average corporate promises that have not been granted attention and legitimacy, which in turn may produce mutuallybeneficial relationships based on dialogue.

From Heidegger's early conception of rhetoric, Zckmund (2007) wrote that "[a]uthenticity is a process of being true to one's own self, of living life according to one's own being" (p. 407). In philosophy, authenticity has been used as the notions of correspondence and genesis. The communication of authenticity goes beyond a plan, program, or campaign. Authenticity is the essence of who the entity is originally with a permanent association to that entity's actions, decisions, and philosophy of living up to its own and others' expectations.

The constant technological changes we are experiencing challenge what is perceived as authentic. What is real and factual in an era of interactive communication and information technology is harder to gauge and confirm, especially for the audiences or publics, because the copy can be a clone of the original. Grayson (2000) stated, "[m]any postmodern writers have argued that technology and commercialism have undermined consumers' ability to tell difference between the real and the fake" (p. 44). This forces us to study authenticity in the context where the communication dynamic occurs and the community of individuals, channels, and tools involved. What was authentic a decade ago may lack authenticity today; similarly, what was considered inauthentic before interactive digital technology arrived and settled, may now be considered original and a genuine and valued reproduction. This points to an emerging territory in which the values and motives behind the building and development of a personal, brand, or organizational identity may be essential for the perception of authenticity by audiences or publics no matter the access they may have to the "original" creation and the creators. Research questions and hypotheses addressing these concerns and ever-changing communication 
environment may perpetuate and enhance the keyword authenticity in the work we do and the content we teach.

\section{THE SCHOLARLY HISTORY IN BRIEF}

Hardt (1993) summarized the historical evolution of the discussion of authenticity from a social theory perspective, particularly critical theory. He explained that the notion of authenticity in the study of communication "has moved through the period of a post-1945 rediscovery of the potential of critical discourse within Western Marxism-as a source of emancipation for the individual-and the rise of liberal democratic practices in Western Europe, accompanied by an Americanization of everyday life" (p. 49). Hardt addressed authenticity and alienation as problems of modernity and also introduced the reaction of critical theorists to an ideology of authenticity.

Scholars have articulated and explored the construct of authenticity to study, for example, films (Hart \& Woldemariam, 2008; Pierson, 2003), journalistic practices of tabloids (Bromley, 2003), media representation of ethnic identity (Molina, 2006), music genres (Herman E Sloop, 1998; McLeod, 1999; Peterson, 1997), political discourse (Liebes, 2001), reality television shows (Aslana $\mathcal{E}$ Pantti, 2006; Kraidy, 2009), rhetoric (Dickinson, 2002; Hasian, 2005; Zickmund, 2007), self identity (Holt \& Griffin, 2009), television broadcasting productions (Montgomery, 2001; Piccirillo, 1986), and virtual reality (Jones, 1993).

In particular, McLeod (1999) studied hiphop as a culture threatened with assimilation and searching for the preservation of an African American identity. He explained that "authenticity has been invoked by hip-hop fans and artists throughout the 1990s, spoken in terms of being 'true,' 'real,' or 'keepin' it real'" (p. 136). Artists and fans "preserved this identity by invoking the concept of authenticity in attempting to draw clearly demarcated boundaries around their culture" (p. 136). Creators and users or followers are engaged in an ongoing negotiation of meanings.

McLeod (1999) examined the discourse of the hip-hop community with a dataset that included more than 800 authenticity claims. He inductively identified six major semantic dimensions of meaning that may be active when the members of the hip-hop community invoke authenticity: (1) Staying true to yourself versus following mass trends (social-psychological dimension), (2) black versus white (racial dimension), (3) underground versus commercial (political-economic dimension), (4) hard versus soft (gender-sexual dimension), (5) the street versus the suburbs (social-locational dimension), and (6) the old school versus the mainstream (cultural dimension). McLeod (1999) concluded that "[s]emantic dimensions are used to demonstrate how authenticity claims and their meaningful structured place within a play of discourse can highlight a culture's key symbols as they employed to maintain a 'pure' identity" (p. 148). Thus, authenticity is subjective and contextual; that is, authenticity claims reflect the life experiences and aspirations of a segment of the society.

Authenticity has been used to study reality television as a media phenomenon in which contestants apparently are spontaneous and unrehearsed; that is, these are moments of truth or presumptive connection to reality in the context of this media genre (Aslana \& Pantti, 2006; Kraidy, 2009). According to Kraidy (2009), this staged reality may be socially and morally contrasting to the reality lived by the audience or witnesses. "Star Academy [a pan-Arab reality show] viewers therefore become agents in the creation of a contemporary [alternative] social reality that clashes head on with regnant Saudi definitions of authenticity," Kraidy explained (2009, p. 361, italics in original). The 
alternative social reality of "unbridled gender and cultural mixing" undermines "the core principles of the prevalent social order" (p. 362). Discourses and claims of authenticity will lose credibility when they clash with the established and accepted values and beliefs of a society that are being portrayed by media products.

Molina (2006) citing Griffiths (1995) stated that "[d]iscourses of authenticity override the complexity of difference, erase the voice of the group being represented, and may be used to create social hierarchies" (p. 235). She analyzed the global media representation of Frida Kahlo as a popular international Mexican icon by arguing that "the question becomes whether global commodity culture can sustain syncretic identity constructions of authenticity" (p. 248). The attempt to reconcile differing understandings and perceptions of a cultural product from audiences all over the world poses a challenge for the creator of a consistent global identity which faces local nuances and interpretations; this is an issue of standardization and localization.

In brief, the power to create and consolidate authenticity claims of media products does not only reside in encoders, but also in decoders; that is, they are product of an ongoing negotiation of meanings. The encoders use relevant symbols accepted as features of the portrayed identity, which must reflect experiences and expectations of the target segment of society-the objective audience. In other words, the values and beliefs of the society should be reflected in authenticity claims to cause the desire effect and establish a true dialogue and exchange of shared meanings between media producers and consumers.

\section{Conceptualizing the Construct in Strategic Communication}

As stated in the introduction, the focus of the keyword "authenticity" in this article is on the definitions and uses of the construct in strategic communication (i.e., advertising, marketing, and public relations). Authenticity is central to the study and practice of strategic or integrated communication and its specialized fields. Scholars with this orientation have used authenticity to study consumers' experience with market offerings (Bruner, 1994; Grayson, 2000; Grayson E Martinec, 2004; Gustafsson, 2006), Tourism experience and destinations (Cohen, 1988; Hughes, 1995; MacCannell, 1973; Wang, 1999), materiality of rhetoric in a corporate case (Dickinson, 2002), CEO portraits (2005), luxury wines (Beverland, 2005; Beverland E Luxton, 2005), subculture of consumption (Leigh, Peters, $\mathcal{E}$ Shelton, 2006), paradox and genres (Gilmore E Pine, 2007), corporate social responsibility and sustainability (Camilleri, 2008), local and global campaigns (Molleda E Roberts, 2008), and the food and beverage industry (Beverland, Lindgreen, $\mathcal{E}$ Vink, 2008). Kent Grayson and his colleagues have offered one of the most thorough examinations of the construct authenticity within the field of marketing to date.

Derived from consumers' personal experience, authenticity is denoted via physical attributes (indexically) and brand essence (iconically) (Grayson, 2002; Grayson E Shulman, 2000; Grayson $\mathcal{E}$ Martinec, 2004). The degree of originality and the extent of genuineness judged by consumers' experiences according to an absolute, objective criterion define indexical authenticity (MacCannell, 1973). The quality perceived, not the absolute but the relative and contextually determined, and the symbolic constructive interpretation of certain expectation projected onto the objects by consumers, explain what is titled iconic authenticity (Cohen, 1988; Bruner, 1994). Grayson and Martinec (2004) explained that "[t]he cues for communicating and perceiving authenticity are at the foundation of this dialogue between marketers and consumers over what is (or is not) authentic, and understanding and 
specifying these cues is an important step in the process of understanding this negotiation of meaning" (p. 310). We have come again in a circle in which the identity crafted and portrayed faces the test of audiences or consumers who in the end, through their personal judgment, grant validity and acceptance to corporate promises and their responses to the claims communicated.

Authenticity has been found to be associated with major companies' brands, and it is central to consumer roles within almost every subculture and consumption context (Leigh, Peters, E Shelton, 2006). Tradition, culture, and craft have been used to create a powerful corporate identity of authenticity (Beverland et al., 2008). Along the same lines, Beverland and Luxton (2005) indicated that cultural sources of communication strategies are widely applied to authenticity identity-building in luxury wine companies. One of these communication strategies is creating (and/ or telling) a sincere story. According to Beverland (2005), creating a sincere story requires a creative combination of industrial or operational and rhetorical attributes. Thus, sincerity is achieved through the public confirmation of hand-crafted techniques; uniqueness; relationship to place; passion for production; and the simultaneous denunciation of commercial motives, rational production methods, and the use of modern strategic communication techniques.

Additionally, Beverland (2005) categorized seven elements to create the image of authenticity in luxury goods. These elements include, first, protecting status, which means that luxury brands represent the highest stage a brand can achieve in terms of value. The identification of status-based positioning of luxury brands is to retain their equity. Second, real commitments to quality, which means that luxury brand history and stories are related directly to real commitments to production quality. Third, price performance, which implies being able to demonstrate actual continuous product quality and the existence of price premiums as a critical element for protecting status. Fourth, using place as a referent, expressed in the commitment to terroir, which is originally a French term in wine, coffee, and tea used to denote the special characteristics that geography bestowed upon them. It can be loosely translated as "a sense of place" which is embodied in certain qualities, and the sum of the effects that the local environment has had on the manufacturing of the product. The use of terroir as a positioning statement and guiding philosophy reinforced a point of uniqueness, granting authenticity to the product.

The fifth element is traditional production methods. The linking of the brand to place or traditional methods of production led the luxury brands to seek protection for the use of that name, and traditional expressions represented the images of craft production. The sixth is stylistic consistency, which is associated with remaining true to past styles while adapting to changing consumer tastes. The brand icon or style illustrates the legend and timelessness of the brand and the intrinsic qualities established over time. The last element is history and culture as referents, which means that making links to the past enhances brand sincerity. This is another resource to ensure authenticity by drawing on historical associations and building links to cultural events. Authenticity is communicated through heritage and links with past events, resulting in the continuance of myths regarding the production processes of certain style icons.

Gilmore and Pine (2007) categorized what a company sells to a customer, termed as "economic offerings," as commodities, goods, services, experiences, and transformations (p. 46). The five types of economic offerings constitute the progression of economic value, which frames and explores the possibilities and scope of authenticity in five genres: 
Commodities-Natural authenticity: People tend to perceive as authentic that which exists in its natural state in or of the earth, remaining untouched by human hands; not artificial or synthetic.

Goods-Original authenticity: People tend to perceive as authentic that which possesses originality in design, being the first of its kind, never before seen by human eyes; not a copy or imitation.

Services-Exceptional authenticity: People tend to perceive as authentic that which is done exceptionally well, executed individually and extraordinarily by someone demonstrating human care; not unfeelingly or disingenuously performed.

Experiences-Referential authenticity: People tend to perceive as authentic that which refers to some other context, drawing inspiration from human history, and tapping into our shared memories and longings; not derivative or trivial.

Transformations-Influential authenticity: People tend to perceive as authentic that which exerts influence on other entities, calling human beings to a higher goal and providing a foretaste of a better way; not inconsequential or without meaning. (pp. 4950 , bold and italics in original)

Gilmore and Pine (2007) detailed each genre in a more explicit way, and they defined particular principles for each genre. They advised that in any market or corporate offer appealing to authenticity, one or more of these five genres, and usually all five, are encountered. The authors presented five axioms for analysis:

If you are authentic, then you don't have to say you're authentic.

If you say you're authentic, then you'd better be authentic.

It's easier to be authentic, if you don't say you're authentic.
It's easier to render offerings authentic, if you acknowledge they're authentic.

You don't have to say your offerings are inauthentic, if you render them authentic. (p. 90, italics in original)

Beverland et al., (2008) identified three forms of authenticity in line with the principles above: Pure (literal), approximate, and moral authenticity. Pure (literal) authenticity is to provide consumer with in situ guarantee of the genuine article; approximate authenticity is to provide consumer with a feeling that this brand will help achieve selfauthentication through a connection with place and time; and moral authenticity is to provide consumer with a feeling that this brand will help achieve self-authentication though the association with personal moral values.

Molleda and Roberts (2008) went beyond brand analysis to study a "glocal" strategic communication campaign sponsored by the National Federation of Coffee Growers of Colombia. The aims of the campaign were to invigorate the identification of coffee growers with their lands and the industry with a nation-building communication effort and to reaffirm the leadership of Colombia as a top world coffee producer with an international media relations plan. The author used Gilmore and Pine's genres of authenticity to assess the perceived genuine nature of a key component of the strategic communication campaign, the Colombian coffee ambassador Juan Valdez. Molleda and Roberts (2008) summarized the forms in which the authenticity genres were found in the case:

[N]atural authenticity in the fact that coffee is a commodity that exists in a natural state, original authenticity as Colombia being the first country to stamp country-of-origin to a world commodity, and exceptional authenticity as Colombia's coffee production is based on human care since the moment the beansarehandpicked until they are delivered to the world market 
by an authentic coffee grower functioning as spokesperson or international icon. The campaign of the new Juan Valdez also conveys referential authenticity, in which the background and experience of this idyllic coffee grower is a human story focused on shared memories and longings of the Colombian community of coffee growers and worldwide coffee consumers, and conveys influential authenticity in that the campaign calls for the preservation of the natural environment expressed by the accord signed between the Federation and Rainforest Alliance. (p. 169, italics in original)

Camilleri (2008) also used a case study to explain the primary role of trust and collaboration in articulating an Australian wine company's authenticity. She argued that "the less time there is for consumers to choose for themselves and evaluate the trustworthiness of certain brands, the more important it is for brands to be authentically trustworthy" (p. 58). The author finally stated that "making organizational actions transparent, aligning brand values with organizational values, and communicating that the brand is a good citizen are necessary steps that ... [the wine company] must take to demonstrate trustworthiness and willingness to engage in trust relationships with consumers and members of the value chain alike (p. 59).

Grayson and Martinec (2004) said that "authenticity can be both a social construction and a source of evidence" and that "the perception of authenticity can depend on the simultaneous application of imagination and belief" (p. 310). The evidence is made available by organizations themselves through actions and operations and their strategic communication function through telling sincere stories and building long-lasting relationships. Then the consumers, audience, or publics while interacting with the corporate promise or offering, would socially construct the perceived authenticity of the organization. Thus, the further understating of authenticity from a strategic communication approach would require an assessment of the organizational crafting of authenticity claims and the consumers' or publics' perception of these claims. This promises to be an evolving and dynamic interaction that is affected by the context and the relevance of the claim for the specific group of consumers or publics.

In summary, Camilleri (2008) synthesized the types of perceived authenticity genres from a strategic communication perspective:

1. Existential authenticity ...driven by and coincides with postmodern consumers' quest for pleasure and fun...

a. Intrapersonal authenticity ... centers on the individual self and involves both physical ... and psychological ... aspects [Wang, 1999].

b. Interpersonal or social authenticity ... focuses on a collective sense of self. In this perspective, an object or experience serves as a tool to bring individuals together for authentic interpersonal relationships [Wang, 1999].

2. Exceptional authenticity ... done, executed, or performed individually or with profound sincerity, care, and feeling (Gilmore \& Pine, 2007).

3. Iconic authenticity ... an accurate reproduction of the original (Grayson E Shulman, 2000; Grayson E Martinec, 2004).

4. Influential authenticity ... is not consequential or without meaning, exerting influence on other entities, calling human beings to a higher goal and predicting a better way (Gilmore \& Pine, 2007).

5. Natural authenticity ... exists in the natural state, untouched by human hands; not artificial or synthetic... [Gilmore $\&$ Pine, 2007].

6. Original authenticity ... is ... imaginative, creative, or innovative in design: the first of 
its kind; not mimicked or copied (Gilmore $\mathcal{E}$ Pine, 2007).

7. Referential, experiential, or indexical authenticity ... refers to or draws inspiration from some spatio-temporal connection to history (Gilmore \& Pine, 2007; Grayson \& Schulman, 2000; Grayson $E$ Martinec, 2004).

8. Staged authenticity ... is based on an object's degree of originality or an individual's personal experience of originality (Cohen, 1988; MacCannell, 1973).

9. Symbolic authenticity ... allows for different interpretations of reality on the basis of consumers' projections onto objects and is essentially symbolic (Culler, 1981). (pp. 48-49)

\section{RELEVANCE OF THE STUDY OF AUTHENTICITY TO CURRENT STRATEGIC COMMUNICATION DEBATES}

Cook (2007) writing in The Public Relations Strategist, a trade publication of the Public Relations Society of America, introduced future trends to better understand the issues facing strategic communication professionals and their clients. Cook stated:

We're at the start of an era where people want authentic stories about authentic people. PR Ipublic relations and strategic communication] professionals are the storytellers. It's our job to help find the authenticity at the core of our companies and clients, and to tell those stories to the world in words that will truly be heard. (p. 33)

In addition to be true to one self; the products, services, and ideas we promote or advocate for; and the organizations we represent, an authentic claim requires authentic communication (Camilleri,
2008). The consistency between the genuine nature of corporate offerings and their communication is crucial to reach more active publics and consumers, to attend the challenges of the emergence of the experience economy, ${ }^{1}$ to overcome the eroding confidence in major social institutions, and to pay attention to the greater demand for transparency and corporate social responsibility. The consistency between authentic claims, offerings, and promises and the management philosophy and behavior of organizations would determine the effectiveness of strategic communication efforts assessed by measuring the responses, actions, and behaviors of audiences, consumers, and/or publics. They are who put the seal of approval to the initiation of a relationship with compatibility of goals, interests, and expectations.

Authenticity communicates what the organization/brand stands for and conveys its core value and tradition (Gilmore \& Pine, 2007). Strategic communication professionals and scholars face other tests when it comes to rendering or studying authenticity, such as the expanded and sophisticated market competition and convergent communication media. This may increase in complexity if we consider the emerging realities of economic systems and consumer or publics demands during and after the national and global recession.

\section{CONCLUSION}

This article introduces and explains the relevance of the construct authenticity for the study and practice of strategic communication. The author now suggests the creation of an authenticity index with the inclusion of statements that operationalize the various types or genres identified by the various authors cited in previous sections.

An authenticity index or scale could then be used to measure effectiveness of strategic communication (public relations and advertising) messages and the perceived authenticity of 
organizations, including its actions, operations, product, services and spokespeople in the mind of internal or external stakeholders or consumers. These research questions could justify the use of a proposed index of authenticity: Does the (interactive, online, print, audiovisual) text or personal message convey any of the following aspects?

- Imagery of or claims that evoke pleasure or fun that could be achieved by consumers or publics, individually or collectively, when they encounter or are exposed to the corporate offering or experience

- Access to the original idea or design, which represents an accurate representation of the original

- Organizational values, including beliefs, principles or way of acting or operating

- Associations with nature of commodities or products, such as being non-renewable or renewable natural resource

- Associations with originality in design of products, services, ideas, or facilities

- Exceptional quality of corporate offerings and operations

- Heritage of the organization and its leaders, as well as mentions to historical background of product and services

- Sustainability and corporate responsibility programs, decisions, or actions

- Calls to become part of an action that goes beyond profit making and corporate gains

- Imagery or claims of consumers' or publics' projections onto the product, service, promise, or idea promoted

A proposed authenticity index should be further develop and tested for internal validity and reliability with the assessment of controlled and uncontrolled communications; the perceptions of public opinion leaders and target stake- holders/consumers' perceptions on the level of authenticity of an organization and its offerings or corporate promises, which could also influence perceived corporate reputation; the exploration of the association between organizational strategic communications and consumers' or publics' perceptions; and the identification of most relevant elements of authenticity depending on the type and timing of the strategic communication effort, as well as the target audience/stakeholder or consumer. Most importantly, a proposed index not only may increase the efficiency and effectiveness of strategic communication, but also may serve as a guiding post to evaluate corporate performance and behavior because "[ilf you say you're authentic, then you'd better be authentic" (Gilmore E Pine, 2007, p. 90, italics in original). Similarly, authenticity claims must capture the experiences, aspirations, and expectations of the involved segment of society that organizations aim to engage; otherwise, a clash a values and beliefs may occur and the strategic communication efforts may be lost.

1. The term is first described in a book written in 1999 by Pine and Gilmore titled The experience economy, in which they describe the experience economy as a next economy following the agrarian economy, the industrial economy, and the most recent service economy. They explained that businesses must orchestrate memorable events for their consumers and, therefore, provide opportunities for them to be in contact, try, or test products and services. Consequently, that memory itself becomes the product - the experience.

\section{REFERENCES}

Adorno, T. (1973). The jargon of authenticity. Evanston, IL: Northwestern University Press.

Aslana, M., E Pantti, M. (2006). Talking alone: Reality TV, emotions and authenticity. European Journal of Cultural Studies, 9(2), 167-184. 
Authentic. (2009). In Merriam-Webster Online Dictionary. Retrieved August 6, 2009, from http://www. merriam-webster.com/dictionary/authentic

Beverland, M. B., Lindgreen, A., E Vink, M. W. (2008). Projecting authenticity through advertising: Consumer judgments of advertisers' claims. Journal of Advertising, 37(1), 5-15.

Beverland, M. B. (2005). Crafting brand authenticity: The case of luxury wines. Journal of Management Studies, 42(5), 1003-29.

Beverland, M. B., \& Luxton, S. (2005). Managing integrated marketing communication (IMC) through strategic decoupling: How luxury wine firms retain brand leadership while appearing to be wedded to the past. Journal of Advertising, 34(4), 103-116.

Bromley, M. (2003). Objectivity and the other Orwell: The tabloidism of the Daily Mirror and journalistic authenticity. Media History, 9(2), 123-135.

Bruner, E. (1994). Abraham Lincoln as authentic reproduction: A critique of postmodernism. American Anthropologist, 96(2), 397-415.

Camilleri, C.S. (2008). True blue: Authenticity and Yalumba's journey of discovery. Australian Journal of Communication, 35(3), 41-67.

Cohen, E. (1988). Authenticity and commoditization in tourism. Annals of Tourism Research, 15(3), 371-386.

Cook, F. (2007, Winter). It's a small world alter all: Multiculturalism, authenticity, connectedness among trends to match in next 50 years. The Public Relations Strategist, 13(1), 30-33.

Culler, J. (1981). Semiotics of tourism. American Journal of Semiotics, 1(1-2), 127-140.

Dickinson, G. (2002). Joe's rhetoric finding authenticity at Starbucks. Rhetoric Society Quarterly, 32(4), $5-27$.

Fine, G. A. (2003). Crafting authenticity: The validation of identity in self-taught art. Theory and Society, 32, 153-80.

Frosh, P. (2001). To thine own self be true: The discourse of authenticity in mass cultural production. The Communication Review, 4, 541-557.

Gilmore, J.H., E Pine, B.J., Jr. (2007). Authenticity: What consumers really want. Boston, MA: Harvard Business School Press.
Grayson, K. \& Martinec, R. (2004). Consumer perceptions of iconicity and indexicality and their influence on assessments of authentic market offerings. Journal of Consumer Research, 31, 296-312.

Grayson, K. (2002). Telling the difference: Consumer evaluations of authentic and inauthentic marketing offerings. Advances in Consumer Research, 29, 44-45.

Grayson, K., E Schulman, D. (2000). Indexicality and the verification function of irreplaceable possessions: A semiotic analysis. Journal of Consumer Research, 27, 17-30.

Griffiths, G. (1995). The myth of authenticity. In B. Ashcroft, G. Griffiths, \& H. Tiffin (Eds.), The post-colonial studies reader (pp. 237-241). London: Routledge.

Gustafsson, C. (2006). Brand trust and authenticity: The link between trust in brands and the consumer's role on the market. European Advances in Consumer Research, 7, 522-527.

Guthey, E. E Jackson, B. (2005). CEO portraits and the authenticity paradox. Journal of Management Studies, 42(5), 1057-1082.

Hardt, H. (1993). Authenticity, communication, and critical theory. Critical Studies in Mass Communication, 10, 49-69.

Hart, K.P., \& Woldermariam, M. (2008). Oprah Winfrey as melodramatic actress: Contributions ofWinfrey's feature-film performances to the authenticity of her star persona. Quarterly Review of Film \& Video, 25(3), 183-195.

Hasian, M., Jr. (2005). Authenticity, public memories, and the problematics of post-Holocaust remembrances: A rhetorical analysis of the Wilkomirski affair. Quarterly Journal of Speech, 91(3), 231-263.

Herman, A., E Sloop, J. (1998). The politics of authenticity in postmodern rock culture: The case of Negativland and The Letter ' $U$ ' and the Numeral '2'. Critical Studies in Mass Communication, 15(1), 1-20.

Holt, M., E Griffin, C. (2009). Being gay, being straight and being yourself: Local and global reflections on identity, authenticity and the lesbian and gay scene. European Journal of Cultural Studies, 6(3), 404-425.

Hughes, G. (1995). Authenticity in tourism. Annals of Tourism Research, 22, 781-803. 
Jones, S. (1993). A sense of space: Virtual reality, authenticity and the aural. Critical Studies in Mass Communication, 10(3), 238-252.

Kraidy, M. (2009). Reality television, gender, and authenticity in Saudi Arabia. Journal of Communication, 59(2), 345-366.

Leigh, T. W., Peters, C., E Shelton, J. (2006). The consumer quest for authenticity: The multiplicity of meanings within the MG subculture of consumption. Journal of the Academy of Marketing Science, 34(4), 481-493.

Liebes, T. (2001). 'Look me straight in the eye:' The political discourse of authenticity, spontaneity, and sincerity. Communication Review, 4(4), 499-510.

Mcleod, K. (1999). Authenticity within hip-hop and other cultures threatened with assimilation. Journal of Communication, 49(4), 134-150.

MacCannell, D. (1973). Staged authenticity: Arrangements of social space in tourist settings. American Journal of Sociology, 79(3), 589-603.

Molina, I. (2006). Mediating Frida: Negotiating discourses of Latina/o authenticity in global media representations of ethnic identity. Critical Studies in Media Communication, 23(3), 232-251.

Molleda, J.C., E Roberts, M. (2008). The value of "authenticity" in "glocal" strategic communication: The new Juan Valdez campaign. International Journal of Strategic Communication, 2(3), 154-174.
Montgomery, M. (2001). The uses of authenticity: "Speaking from experience' in a U.K. election broadcast. Communication Review, 4(4), 447-462.

Oxford English Dictionary. (1989). Prepared by J. A. Simpson and E. S. C. Weiner. Oxford, UK: Oxford University Press.

Peterson, R.A. (1997). Creating country music, fabricating authenticity. Chicago, IL: University of Chicago Press.

Person, D. (2003). Turner Network Television's madefor-tv Western films and the social construction of authenticity. Film \& History, 33(2), 55-64.

Piccirillo, M.S. (1986). On the authenticity of televisual experience: A critical exploration of para-social closure. Critical Studies in Mass Communication, 3(3), 337-355.

Pine, J., \& Gilmore, J. (1999). The experience economy. Boston, MA: Harvard Business School Press.

Trilling. L. (1972). Sincerity and authenticity. Cambridge, MA: Harvard University Press.

Zickmund, S. (2007). Deliberation, phronesis, and authenticity: Heidegger's early conception of rhetoric. Philosophy \& Rhetoric, 40(4), 406-415.

Wang, N. (1999). Rethinking authenticity in tourism experience. Annals of Tourism Research, 26(2), 349370. 